\title{
ORIGINAL ARTICLE Balance between inbreeding and outcrossing in a nannandrous species, the moss Homalothecium lutescens
}

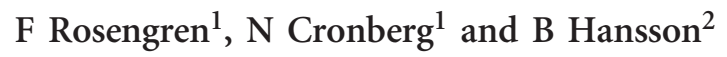

Epiphytic dwarf males on the females present a possible solution to the problem of short fertilization distances in mosses. However, leptokurtic spore dispersal makes dwarf males likely to be closely related to their host shoot, with an accompanying risk of inbreeding. The capacity of a female to harbour a high number of different dwarf males suggests that there may be mechanisms in place that counteract inbreeding, such as polyandry and post-fertilization selection. We have genotyped sporophytes, female host shoots and dwarf males in four populations of the moss Homalothecium lutescens. We found no evidence of selective sporophyte abortion based on level of heterozygosity. The occurrence of entirely homozygous sporophytes together with significantly positive inbreeding coefficients in three of the populations (mean $F_{\text {IS }}$ between 0.48 and 0.64 ) suggest frequent mother-son mating events. However, $23 \%$ of all sampled sporophytes had a higher level of heterozygosity compared with the mean expected heterozygosity at the population level. Polyandry was frequent, on average $59 \%$ of the sporophytes on a female shoot were sired by distinct fathers. In conclusion, sporadic fertilizations by dwarf males originating from nonhost female shoots appear to counteract strong inbreeding.
\end{abstract}

Heredity (2016) 116, 107-113; doi:10.1038/hdy.2015.79; published online 2 September 2015

\section{INTRODUCTION}

Mating with multiple males (that is, polyandry) may have several benefits in plants; it enables pollen competition (Armbruster and Rogers, 2004; Pannell and Labouche, 2013) and post-fertilization selection (Korbecka et al., 2002) as well as increases the genetic diversity of the offspring (Ellstrand and Marshall, 1986; Cornell and Tregenza, 2007). It has also been shown that polyandry may halt the spread of selfish genetic elements (Price et al., 2008). Hence, polyandry may not only prevent inbreeding but also have significant implications for the evolution of mating systems.

In bryophytes, the potential for polyandry may be limited for at least two reasons. First, fertilization mainly occurs between individuals in close proximity as a consequence of short dispersal range of the swimming spermatozoids (Bisang et al., 2004). Hence, the sexual partners are principally limited to the shoots growing in the same colony. Second, local recruitment in bryophytes appears to be restricted by the difficulty of spores to germinate in already established colonies, possibly regulated by chemicals exuded by the mature shoots (Mishler and Newton, 1988; Basile et al., 2003). As a consequence, where disturbance is low, the number of clones that coexist within fertilization distance may be limited (Cronberg et al., 2006, but see for example van der Velde et al., 2001). In vegetatively proliferating perennial species, the genet composition may remain unchanged for many years, leading to few available mating alternatives.

It has been estimated that $10-20 \%$ of all moss species (and at least $25 \%$ of all dioicous perennial pleurocarpous mosses) are nannandrous (also known as phyllodioicous), meaning that the males are situated as tiny epiphytes on a much larger female shoot (Hedenäs and Bisang, 2011). These so-called 'dwarf males' originate from male spores that happen to land on a mature female shoot. After germination the spores form gametophytes restricted to at most a few $\mathrm{mm}$ in size that produce male gametangia (antheridia). Dwarf males may readily establish in mature female colonies, sometimes as many as several hundreds per shoot. Having dwarf males may reduce intersexual competition, by giving more space for females to grow. In addition, the dwarf male sexual system is expected to multiply the number of available mating partners to a female shoot and thus increase the potential for outcrossing and polyandry. Bryophytes are the only known sessile land organisms with epiphytic dwarf males, whereas other organisms with similar mating system are mostly found in aquatic habitats (Ghiselin, 1974; Vollrath, 1998).

The female shoots do not appear to be overly selective regarding which male spores are allowed to germinate on them, as demonstrated by the fact that dwarf males may be able to develop on shoots of closely related species (Rosengren and Cronberg, 2015). Because of the leptokurtic distribution of spore dispersal (Sundberg, 2005), the spores that develop into dwarf males are more likely produced by nearby shoots (or even the same shoot) than arriving from a more distant source. Accordingly, it is not clear to what extent the dwarf male sexual system will lead to outcrossing or inbreeding, relative to similar species without dwarf males. If fertilization between the female host shoot and its own male progeny is common, it could eventually lead to high levels of homozygosity in the sporophytes. Consequently, the female shoot and its male progeny (that will become the next generation of dwarf males) may have a high genetic similarity. High levels of inbreeding have been suggested as a potential consequence of the dwarf male sexual system in bryophytes (Mogensen, 1981; Ramsay, 1985; Hedenäs and Bisang, 2011; Pichonet and Gradstein, 2012). Because of the dominant haploid life stage, inbreeding in bryophytes may have more drastic genetic effects compared with diploids.

${ }^{1}$ Biodiversity, Department of Biology, Lund University, Lund, Sweden and ${ }^{2}$ Molecular Ecology and Evolution Lab, Department of Biology, Lund University, Lund, Sweden Correspondence: Dr F Rosengren, Biodiversity, Department of Biology, Lund University, Ecology Building, SE-223 62 Lund, Sweden. E-mail: Frida.Rosengren@biol.lu.se

Received 26 March 2015; revised 3 July 2015; accepted 9 July 2015; published online 2 September 2015 
Intragametophytic selfing results in 100\% homozygosity, whereas mating between siblings (that is, individuals produced by the same sporophyte, also known as intergametophytic selfing) results in a $50 \%$ reduction of heterozygosity, comparable to selfing in vascular plants (Eppley et al., 2007; Taylor et al., 2007).

A selection of different available sexual partners (that may be the case in species with dwarf males) is a precondition for mechanisms that may counteract inbreeding such as sperm competition and/or post-fertilization selection. Because of the fact that bryophytes generally lack morphological structures facilitating sperm competition (for example, a style), post-fertilization selection is the more likely option. In vascular plants, the number of fertilized ovules often exceeds the number of produced seeds (Korbecka et al., 2002). In bryophytes, each perichaetium (female sexual bud) contains several archegonia (Longton, 1962). A single female shoot may have multiple perichaetia, but only exceptionally do more than one sporophyte develop to full maturity from each perichaetium (Longton and Schuster, 1983; Longton, 1994). Sporophyte production has been shown to be resource limited and abortion of sporophytes in an early developmental stage is not uncommon (Hughes, 1979; Stark and Stephenson, 1983; Stark et al., 2000; Ehrlén et al., 2000). A recent study of Sphagnum lescurii showed that females preferentially supported sporophytes with higher heterozygosity in populations with significant spatial genetic structure (Szövényi et al., 2009). If postfertilization selection based on sporophyte heterozygosity occurs in a moss with dwarf males, the level of heterozygosity in the sporophytes would be higher than what is expected from the available male sexual partners (that is, dwarf males on or nearby the mother shoot).

The main objective of the present study was to investigate whether high levels of inbreeding is a consequence of the dwarf male sexual system, or whether it is counteracted by mechanisms such as polyandry and/or post-fertilization selection. We genotyped female shoots, dwarf males and sporophytes from four populations of the nannandrous moss Homalothecium lutescens and estimated the levels of inbreeding and polyandry. In addition, we tested whether the observed levels of sporophyte heterozygosity were higher than expected from the dwarf males situated on the female host shoots, indicating selective sporophyte abortion.

\section{MATERIALS AND METHODS}

\section{Study species}

H. lutescens is a perennial pleurocarp that proliferates largely by clonal growth. Large shoots with perigonia (that is, fertile males) are rare; none were found in this study and from the literature they are reported to occur approximately once in several hundred females (Lieske, 2010; Rosengren et al., 2014; Rosengren and Cronberg, 2014). The majority of males are situated on the female shoots as dwarf males, no more than at most a few $\mathrm{mm}$ in size. Spore dispersal occurs around February/March and females are fertilized around May/ June (Arnell, 1875; Grimme, 1903). It is not entirely known how fast the dwarf males develop after germination, but field observations (F Rosengren) suggest that dwarf males may fertilize the female the same year they were produced (after a couple of months) and/or over winter and fertilize the female the subsequent year. The prevailing opinion is that the dwarf males are unlikely to be able to live more than 1 or 2 years on the large shoots (Sagmo Solli et al., 1998; Hedenäs and Bisang, 2011; Hedenäs and Bisang, 2012). As dwarf males are frequently sterile, their true sexual identity is often unknown (male and female shoots lack distinguishing characters other than the sexual organs). Consequently, it cannot be ruled out that some dwarf plants are actually dwarf females or young 'normal-sized' females.

\section{Sites and sampling}

Sampling was conducted in November 2012 in four different locations where dwarf males and sporophytes had previously been found in abundance: (1) Arrie ponds (AP, 55 $\left.31^{\prime} 15.3^{\prime \prime} \mathrm{N} 13^{\circ} 6^{\prime} 5.7^{\prime \prime} \mathrm{E}\right)$, (2) Käglinge ponds (KP, $\left.55^{\circ} 31^{\prime} 57.2^{\prime \prime} \mathrm{N} 13^{\circ} 3^{\prime} 57.6^{\prime \prime} \mathrm{E}\right)$, (3) Limhamn quarry (LQ, $55^{\circ} 34^{\prime} 5.7^{\prime \prime} \mathrm{N}$ $\left.12^{\circ} 55^{\prime} 29.0^{\prime \prime} \mathrm{E}\right)$ and (4) Cape Klagshamn (CK, 55 31'21.0” $\left.\mathrm{N} 12^{\circ} 54^{\prime} 2.8^{\prime \prime} \mathrm{E}\right)$. Population AP, KP and $\mathrm{CK}$ are located in partly open, partly forested recreational areas. Population LQ is located in a former opencast pit with large areas of open ground but also partly covered by trees and shrubs. All four populations are located in the south of Sweden within an area of $\sim 60 \mathrm{~km}^{2}$ that mainly consists of arable land and suburban areas around the city of Malmö.

Five colonies (six in population CK) separated by a minimum of $20 \mathrm{~m}$ were selected in each of the four populations. The shoots within the selected colonies should bear sporophytes within an area of at least $0.5 \mathrm{~m}^{2}$. One female shoot was sampled from the centre of each colony, including attached sporophytes and dwarf males. A shoot is defined as the greenish part of the moss down to the brown/black part that detaches from the larger clone when picked up from the ground. Each female shoot may carry anything between 0 and several hundreds of dwarf males and up to $\sim 20$ sporophytes.

\section{DNA extraction}

DNA extraction was performed with Qiagen (Hilden, Germany) DNeasy Plant MiniKit. Between four and six sporophytes from each female shoot were used for DNA extraction. Between 10 and 20 dwarf males were picked off each female shoot and allowed to grow on agarose plates (with a weak nutrient solution) for 4 months before extraction. In total, DNA extraction was performed for 21 female shoots, 239 dwarf males and 108 sporophytes.

\section{SNP genotyping}

Single-nucleotide polymorphism (SNP) extraction from 454 sequenced transcriptome data is described in Supplementary Appendix S1. Potential SNP locus candidates (125) were sent to SciLifeLab (Uppsala, Sweden) who selected 96 SNP loci, based on an Illumina (San Diego, CA, USA) scoring of their functionality and primer designability regarding the GoldenGate assay (Fan et al., 2003). Scores of $0.5-1.0$ are required for a high-quality assay. The 96 SNPs selected in the present study had a score of $\geqslant 0.58$. A UniProt (UniProt Consortium, 2014) database search of the 96 isotigs containing the target SNPs revealed that none of them were transcribed from the chloroplast genome. DNA samples were sent to SciLifeLab who performed SNP genotyping using the Illumina GoldenGate assay (Fan et al., 2003). In total, 368 samples were sent for genotyping: 21 haploid female gametophytes, 239 haploid dwarf male gametophytes and 108 diploid sporophytes. The haploid SNP genotypes (the combination of alleles in a haploid gametophyte) will hereafter be referred to as haplotypes. The haploid paternal haplotypes of the sporophytes (so-called 'fathers') were extracted from the female and sporophyte genotypes. As the diploid sporophyte genotype is a result of fusion between the haploid father and mother genotypes, the father haplotype for each sporophyte was derived by subtracting the mother shoot haplotype from the diploid sporophyte genotype.

\section{Polyandry}

To estimate the level of polyandry, we calculated the number of distinct father haplotypes on each female shoot $(K)$ as well as the proportion of the sampled sporophytes that was sired by distinct fathers. Individuals that shared alleles in all loci except for loci with missing data were treated as the same haplotype. In addition, we calculated the effective number of fathers ( $K_{\mathrm{E}}$, Bernasconi, 2003) on each female shoot using the following equation $K_{\mathrm{E}}=1 / \Sigma\left(p_{\mathrm{i}}\right)^{2}$, where $p_{\mathrm{i}}$ is the proportion of the sporophytes fertilized by each distinct father haplotype. When the distinct fathers each sire an equal number of sporophytes on a female shoot, the effective number of fathers $\left(K_{\mathrm{E}}\right)$ will be the same as the number of distinct fathers $(K)$. To get a general estimate of the level of paternity skew, we calculated the mean value of $K_{\mathrm{E}} / K$ over all female shoots (Szövényi et al., 2009); this index ranges between 0 (high paternity skew) and 1 (no paternity skew).

\section{Inbreeding}

The expected number of heterozygotes in a locus with two alleles may be calculated as $2 \times p \times q$ (where $p$ and $q$ are the frequencies of the two alternative 
alleles). If the allele frequencies in the males and females differ, the expected number of heterozygotes would instead be $p_{\text {mothers }} \times q_{\text {fathers }}+p_{\text {fathers }} \times q_{\text {mothers }}$. From the genotypes of the sporophytes and the host shoots, we were able to derive allele frequencies in the mothers and the fathers in each population. From these allele frequencies, we calculated expected heterozygosity at the population level for each locus $\left(H_{\mathrm{EXP}}\right)$. The observed heterozygosity for each locus $\left(H_{\mathrm{OBS}}\right)$ was derived directly from the sporophyte genotypes. Individuals with missing data were excluded in the calculations of $H_{\mathrm{EXP}}$ and $H_{\mathrm{OBS}}$ within each locus. Wright's coefficient of inbreeding $\left(F_{\mathrm{IS}}=\left(H_{\mathrm{EXP}}-H_{\mathrm{OBS}}\right) / H_{\mathrm{EXP}}\right)$ was calculated for all loci that were polymorphic in both mothers and fathers (number of loci in $\mathrm{AP}=49, \mathrm{KP}=40, \mathrm{LQ}=21$ and $\mathrm{CK}=40$ ) and the mean $F_{\mathrm{IS}}$ within populations was tested against zero in a one-sample $t$-test in $\mathrm{R}$ version 3.1.1 (R Development Core Team, 2005). In addition, the difference in $F_{\mathrm{IS}}$ between populations was tested in analysis of variance in $\mathrm{R}$ (followed by Tukey's HSD (honest significant difference) post hoc test).

The observed level of heterozygosity was calculated for each individual sporophyte, excluding loci with missing data $\left(H_{\mathrm{SP}}\right)$. In each population, the mean expected heterozygosity over the 68 loci was calculated (mean $H_{\mathrm{EXP}}$ ), corresponding to the overall expected frequency of heterozygous loci in each individual.

\section{Post-fertilization selection test}

To test whether sporophytes with a high level of homozygosity had been selectively aborted, we compared the observed level of heterozygosity in the sporophytes on a female shoot $\left(H_{\mathrm{SP}}\right)$ with the theoretical level of heterozygosity in the sporophytes sired by a random set of potential male sexual partners (the sampled dwarf males hosted by the female shoot) $\left(H_{\mathrm{TH}}\right)$. The difference between $H_{\mathrm{TH}}$ and $H_{\mathrm{SP}}$ was tested in a linear mixed effects model with the lmer function (lme4 package) in $\mathrm{R}$ statistical package version 3.1.1. The response variable in the model was the level of heterozygosity in the sporophytes. Sporophyte category (two levels: $H_{\mathrm{TH}}$ and $H_{\mathrm{SP}}$ ) was treated as a fixed effect. Population and female host shoot (nested within population) were treated as random effects. The response variable was log-transformed to meet the model assumptions (normal distributed residuals and homogeneity of variances).

\section{RESULTS}

\section{SNP genotyping}

Of the 96 SNP markers in the GoldenGate assay, 84 resulted in genotyping (that is, allelic data were obtained for at least one individual). However, out of these 84 SNP markers, 13 were monomorphic and 3 failed in $>20 \%$ of the samples, resulting in a total of 68 polymorphic SNPs that were used in further analyses. All sequences containing the SNPs that were used were annotated to a bryophyte (one to Grimmia pilifera, the rest to Physcomitrella patens). Total proportion of missing data (failed genotyping) was $1.3 \%$. No individual had $>10 \%$ missing data and no loci had $>17 \%$ of missing data. The missing data contribute to lower resolution in the genotyping. However, as the number of markers was high (68) and the missing data were more or less evenly distributed among individuals and loci, we do not believe the missing data significantly affected the analyses.

All samples except 30 dwarf males could be SNP genotyped (that is, allelic data were obtained for at least $90 \%$ of the 68 loci). In total, 21 female shoots, 209 dwarf males (mean 10.0 \pm 2.1 dwarf males per female host shoot, ranging between 5 and 12) and 108 sporophytes (mean $5.1 \pm 0.7$ per female host shoot, ranging between 4 and 6 ) were genotyped. Data are given as mean \pm s.d.

\section{Polyandry}

On average, each female shoot hosted (a minimum of) 7.9 distinct dwarf male haplotypes (ranging between 4 and 12), allowing the possibility for polyandry. If we assume that identical father haplotypes derived from sporophytes on two different female shoots $(>20 \mathrm{~m}$ apart) are unlikely to belong to the same individual, the 108 sampled sporophytes were sired by (a minimum of) 65 distinct fathers. Out of all distinct father haplotypes, $66 \%$ were found in only a single sporophyte on the female host, $14 \%$ in two, $11 \%$ in three, $6 \%$ in four and $3 \%$ in five sporophytes. At least 18 of the 21 female shoots had been fertilized by more than one male. On three of these shoots, all of the sampled sporophytes (five in each case) had distinct fathers.

On average, $59 \pm 25 \%$ of the sampled sporophytes on a female shoot were sired by distinct fathers. In raw numbers, the sporophytes on a female shoot (mean sample $5.1 \pm 0.7$ ) were on average sired by $3.1 \pm 1.4$ distinct fathers $(K)$. The mean effective number of fathers $\left(K_{\mathrm{E}}\right)$ on a female shoot was $2.7 \pm 1.4$. Paternity skew $\left(K_{\mathrm{E}} / K\right)$ was estimated to an average of $0.87 \pm 0.21$.

\section{Inbreeding}

The mean inbreeding coefficient $F_{\text {IS }}$ was significantly $>0$ in all populations except for LQ (AP: $t_{(48)}=12.75, P<0.001$; KP: $t_{(39)}=14.07, P<0.001 ; \mathrm{LQ}: t_{(20)}=1.50, P=0.149$; CK: $t_{(39)}=15.28$, $P<0.001)$, and among the populations KP showed highest $F_{\text {IS }}(0.64)$ followed by CK (0.59), AP (0.48) and LQ (0.10; Table 1). Inbreeding $\left(F_{\mathrm{IS}}\right)$ was significantly different between populations in the test including all populations (analysis of variance $\mathrm{F}_{(3)}=21.23$, $P<0.001$ ), and differed between several populations pairs $(t$-tests: CK-KP: $P_{\text {adj }}=0.841$; CK-AP: $P_{\text {adj }}=0.186$; CK-LQ: $P_{\text {adj }}<0.001$; KPAP: $P_{\text {adj }}=0.023$; KP-LQ: $P_{\text {adj }}<0.001$; AP-LQ: $\left.P_{\text {adj }}<0.001\right)$.

The observed level of heterozygosity $\left(H_{\mathrm{SP}}\right)$ in the sporophytes ranged between 0 and 0.46 (Figure 1). A total of 19 sporophytes from 8 different female shoots were homozygous in all loci. On 18 out of 21 female shoots, two or more sporophytes had identical genotypes (missing data ignored) and consequently identical fathers, suggesting the possibility that single males had frequently fertilized female shoots multiple times. Alternatively, the resolution of the SNPs used was too low to distinguish between fathers that were genetically very similar. The mean expected sporophyte heterozygosity over all loci (mean $H_{\text {EXP) }}$ was 0.32 in AP, 0.24 in $\mathrm{KP}, 0.19$ in LQ and 0.23 in CK (Figure 1). A majority of the sampled sporophytes had a lower level of heterozygosity than expected (Figure 1). However, several sporophytes in each population had a higher level of heterozygosity than expected; 5 sporophytes in AP (from 3 shoots), 3 sporophytes in KP (from 2 shoots), 11 sporophytes in LQ (from 2 shoots) and 6 sporophytes in CK (from 2 shoots), equivalent to $23 \%$ of all sampled sporophytes (Figure 1).

\section{Post-fertilization selection test}

For 9 of the 21 female shoots, one or more father haplotypes (mean $51 \pm 31 \%$ ) were represented among the dwarf males sampled from the

Table 1 Mean inbreeding coefficient $\left(F_{\text {IS }}\right)$ over polymorphic SNP loci in four populations of the nannandrous moss Homalothecium lutescens in southern Sweden

\begin{tabular}{lccc}
\hline Pop & $\mathrm{F}_{/ S}($ mean \pm s.d.) & $\mathrm{N}$ (loci) & One-sample t-test against O \\
\hline AP & $0.48 \pm 0.26$ & 49 & $P<0.001$ \\
KP & $0.64 \pm 0.29$ & 40 & $P<0.001$ \\
LQ & $0.10 \pm 0.29$ & 21 & $P=0.49$ \\
CK & $0.59 \pm 0.25$ & 40 & $P<0.001$ \\
\hline
\end{tabular}

Abbreviations: AP, Arrie ponds; CK, Cape Klagshamn; KP, Käglinge ponds; LQ, Limhamn quarry; Pop, population; SNP, single-nucleotide polymorphism. 


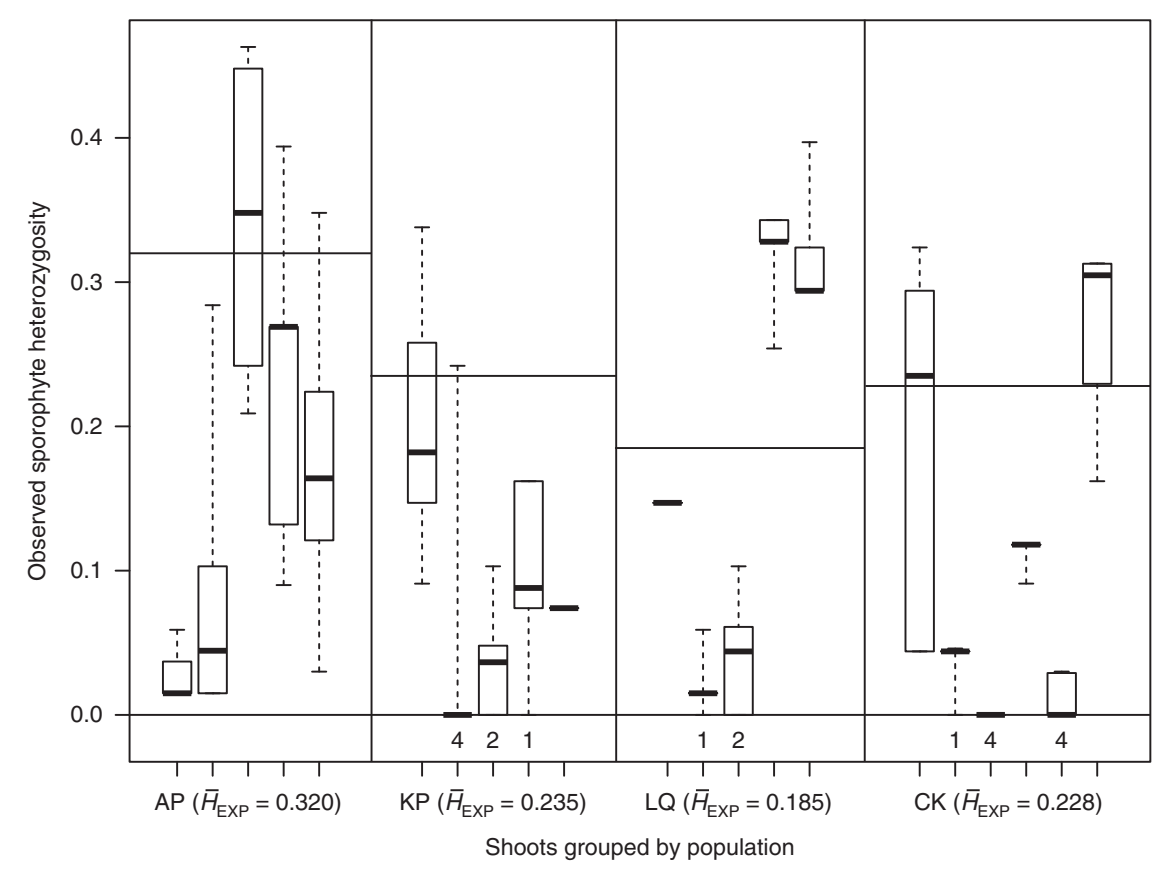

Figure 1 Observed sporophyte heterozygosity in four populations of the nannandrous moss Homalothecium lutescens in southern Sweden. Each box represents between four and six sporophytes on a single female shoot. The delimitations of the boxes on the y axis represent the lower and upper quartile, thick horizontal lines within boxes represent the median and whiskers delimit the total range of the data (minimum and maximum values outside of the quartiles). Horizontal lines within each population represent mean $H_{\text {EXP }}$ in each population (that is, expected heterozygosity averaged over all loci, based on male and female allele frequencies; for details see text). Most sporophytes fall below the line and could be defined as inbred, but several exceptions occur. Numbers below the $\mathrm{y}=0$ line represent the number of sporophytes on the shoot that are homozygous in all loci.

same female. In total, $22 \%$ of all distinct father haplotypes in the study were represented in the sampled dwarf males. The father haplotypes that were not represented in the sampled dwarf males may originate from unsampled dwarf males present on the female shoot, other dwarf males within fertilization distance (on neighbouring shoots) or dwarf males that have died and disappeared since the fertilization period. There was no difference in observed heterozygosity level between the sampled sporophytes $\left(H_{\mathrm{SP}}\right)$ and the theoretical sporophytes sired by the dwarf males on a female host shoot $\left(H_{\mathrm{TH}}\right) \quad\left(\mathrm{F}_{(1,295)}=0.93\right.$, $P=0.34$; Figure 2).

\section{DISCUSSION}

Dwarf males occur in a large variety of different organisms and have likely evolved for several different reasons. It is possible to imagine that in some environments, epiphytic dwarf males have evolved purely as an ecological adaptation, for example, to reduce competition between the sexes. In such cases, inbreeding may turn out to be a negative side effect. Our results show that this is not necessarily true. In the moss $H$. lutescens, we found that polyandry was frequent; on average, female shoots carried sporophytes sired by at least three different males. The level of heterozygosity in the sporophytes varied between shoots and was occasionally high, despite significant levels of inbreeding within three of the populations.

\section{Frequent polyandry}

The female shoots support a relatively large number of distinct dwarf males, and on average a minimum of 7.9 distinct haplotypes were found on a single female host. Polyandry appears to be the rule rather than the exception in the sampled populations of $H$. lutescens, and an average of $59 \%$ of the sporophytes on each female shoot had been sired by distinct fathers. All but three females had been fertilized by more than one male (Figure 1). The average level of paternity skew was moderate $(0.87)$ and the mean number of effective fathers on a single female (2.7) was close to the actual number of distinct fathers (3.1). The spatial separation of the (often numerous) branches from which the perichaetia are produced (F Rosengren, personal observation) likely reduces the chance of a single male fertilizing all archegonia. Frequent polyandry has previously been reported for S. lescurii, where on average $64 \%$ of the sporophytes on each female shoot had been sired by distinct fathers (Szövényi et al., 2009). Mating with multiple males is a prerequisite for the possibility of post-fertilization selection and could thus be essential in populations where such mechanisms have developed (for example, to prevent inbreeding). It is important to notice that frequent polyandry means that the effective size of populations is increased because more males are involved in mating. Thus, the risk for genetic drift is decreased (cf. Bengtsson and Cronberg, 2009).

On the other hand, a large majority of the female shoots had one or more sporophytes with identical genotypes, suggesting either that single dwarf males have fertilized a female multiple times, or that some females have been fertilized by several identical male individuals. The likelihood for different dwarf males to fertilize a female probably varies markedly and is related to both timing and placement. Female shoots are only fertile during late spring/early summer (Arnell, 1875; Grimme, 1903). Hence, the dwarf males that are fertile at the same time as the females have a great fertilization advantage. In addition, the placement of the dwarf male in relation to the perichaetia should be of large importance and could perhaps partly explain the observed paternity skew. 


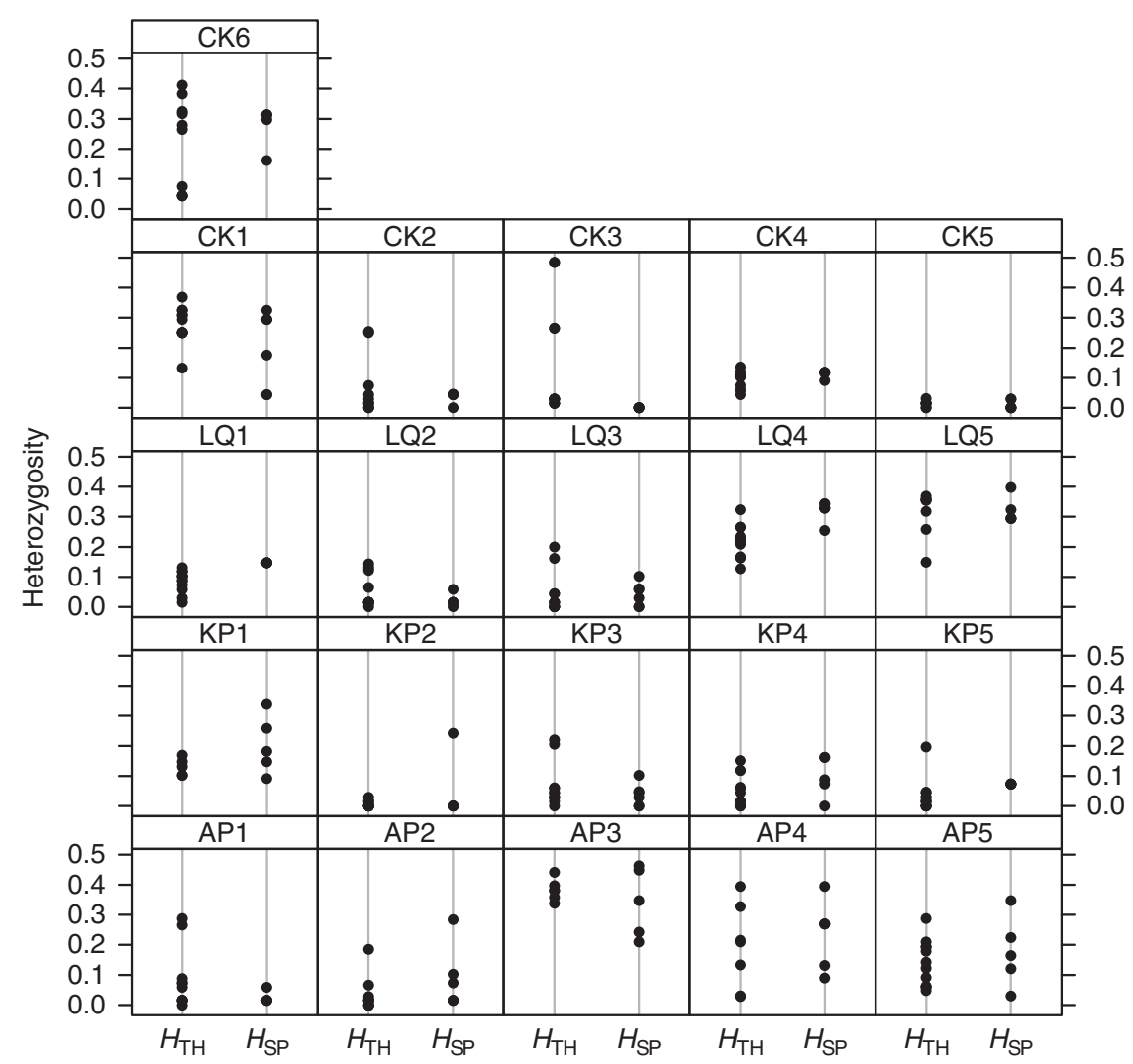

Figure 2 Observed heterozygosity in the sporophytes $\left(H_{S P}\right)$ and in the theoretical sporophytes resulting from fertilization between hosted dwarf males and the female host shoot $\left(H_{T H}\right)$ on 21 female shoots within four populations (AP, KP, LQ and CK) of the moss Homalothecium lutescens. There was no significant difference between $H_{S P}$ and $H_{T H}$, indicating that the males that sire sporophytes are a random sample of the potential male sexual partners regarding the level of heterozygosity (that is, no selective abortion of highly homozygous sporophytes).

\section{Inbreeding}

Heterozygote deficiency $\left(F_{\mathrm{IS}}\right)$ has previously been estimated to be $\sim 0.41 \pm 0.11$ for dioicous bryophytes (based on five different species, Eppley et al., 2007). We detected higher values in three of the studied populations $(0.64,0.59$ and 0.48 , respectively), and lower in one population (0.10) (Table 1). Significant deviation from HardyWeinberg equilibrium $\left(F_{I S}>0\right)$ in three of the four populations can possibly be attributed to significant population spatial structure (F Rosengren et al., unpublished data).

A majority of the sporophytes had an overall lower level of heterozygosity than expected from the allele frequencies at the population level. In three of the populations, sporophytes with $100 \%$ homozygosity were found, and this could possibly be explained by repeated inbreeding. If dwarf males are frequently produced by sporophytes on their host shoot, mating between mother and son may be common. Because of the shoots being haploid, each mating between mother and son reduces on average the heterozygosity level by $50 \%$. If we start off with a heterozygosity level of for example 0.24 (the average in population $\mathrm{KP}$ ), it would theoretically require no more than five cycles of mother-son mating events to reach $1 \%$ heterozygosity (equivalent to total homozygosity in 68 markers). However, the level of heterozygosity in the sporophytes varied markedly between (and within) female shoots and none of the populations had consistently high levels of homozygosity (Figure 1). Several sporophytes (distributed between all populations) had a higher heterozygosity level than expected, suggesting outcrossing. Hence, although inbreeding does occur, there are several exceptions where a female shoot appears to have been fertilized by a dwarf male produced by a sporophyte on another female. The dwarf male in question may have been hosted either by the female that was fertilized or another nearby shoot.

\section{No evidence of post-fertilization selection}

Because of the fact that bryophytes have limited possibility to assess mate quality before fertilization (Szövényi et al., 2009), postfertilization selection could potentially be an efficient way of increasing the fitness of the sporophytes. However, we found no evidence of post-fertilization selection favouring more heterozygous sporophytes in the sexual reproduction.

Observations in the field (F Rosengren) suggest that some dwarf males of $H$. lutescens are able to over winter and fertilize the female the year after they were produced. Consequently, the sporophytes sampled in this study may have been sired by a mix of dwarf males produced the same year (that is, the sampled dwarf males) and the year before. Varying levels of sexual reproduction and spore dispersal between years could mean that dwarf males from two cohorts differ regarding the general level of relatedness to the female host. Hence, the observed level of heterozygosity in the sporophytes may be higher than expected from the sampled dwarf males for other reasons than post-fertilization selection. However, our results suggest that the dwarf males that sire sporophytes are more or less a random subset of the available mating partners, although there appears to be some paternity skew in that some dwarf males sire more sporophytes than others (possibly as a result of fortunate timing or placement). 
One consequence of the dominant haploid life stage in bryophytes is that deleterious recessive alleles are expected to be purged rather efficiently from the population (Eppley et al., 2007; Taylor et al., 2007; Szövényi et al., 2014). As a consequence, inbreeding depression may be low even in populations that experience frequent inbreeding. The life stage that is most likely to suffer from inbreeding depression is the diploid sporophytic phase (Taylor et al., 2007). The studies that have attempted to address the relationship between heterozygosity and fitness in sporophytes of various bryophyte species have rendered conflicting results, suggesting that inbreeding depression may be present under certain circumstances but not others (Taylor et al., 2007; Szövényi et al., 2009; Perroud et al., 2011; Jesson et al., 2012; McDaniel and Perroud, 2012; Johnson and Shaw 2015). If the level and risk of inbreeding depression varies greatly between different populations, the selection pressure to avoid inbreeding is also expected to differ. Hence, in the studied populations, selection favouring postfertilization selection may have been weak. To get a deeper understanding of the potential consequences of inbreeding in bryophytes, the relative importance of inbreeding depression needs to be further investigated in populations with different mating systems.

\section{CONCLUSIONS}

Bryophytes (mosses, liverworts and hornworts) and spore-producing tracheophytes (lycophytes and pteridophytes) have motile sperm that need a water surface for transportation; a mechanism retained from their algal ancestors. This type of fertilization is considered to be an evolutionary constraint in terrestrial environments because of dependence of water and restricted fertilization distances. Nannandry can be seen as an adaptation to overcome this constraint. However, concerns have been raised that nannandry would lead to serious inbreeding and loss of genetic variation. Here we provide unique data on polyandry and inbreeding levels in a nannandrous species. Our results show that females were frequently fertilized by several different males. Furthermore, sporadic fertilization of dwarf males originating from nonhost females appears to counteract serious inbreeding. Genetic studies in species with dwarf males are desperately few, and this means it is difficult to draw conclusions about whether our findings would also apply for other organisms. To fully understand the evolution of the dwarf male sexual system, results from the various kinds of organisms with this reproductive system need to be evaluated and compared.

\section{DATA ARCHIVING}

The SNP genotypes of all the samples as well as the sequences for the 68 used SNP markers are available from the Dryad Digital Repository at http://dx.doi.org/10.5061/dryad.1860s. All isotigs used for the SNP extraction are stored in an annotated database available at http://mbio-serv2.mbioekol.lu.se/Mosses.

\section{CONFLICT OF INTEREST}

The authors declare no conflict of interest.

\section{ACKNOWLEDGEMENTS}

This study was supported by grants from The Royal Physiographic Society in Lund, Elly Olssons fund and Ove Almborns fund (to FR). We thank the 454 sequencing platform in Lund University (Science Faculty) for valuable support during the whole process of sequencing and extracting SNP markers. Genotyping was performed by the SNP\&SEQ Technology Platform in Uppsala that is part of Science for Life Laboratory at Uppsala University and is supported as a national infrastructure by the Swedish Research Council (VR-RFI).
Armbruster WS, Rogers DG (2004). Does pollen competition reduce the cost of inbreeding? Am J Bot 91: 1939-1943.

Arnell WH (1875). De skandinaviska lövmossornas kalendarium. PhD thesis, University of Uppsala.

Basile A, Sorbo S, López-Sáez JA, Castaldo Cobianchi R (2003). Effects of seven pure flavonoids from mosses on germination and growth of Tortula muralis HEDW.(Bryophyta) and Raphanus sativus L.(Magnoliophyta). Phytochemistry 62 . 1145-1151.

Bengtsson BO, Cronberg N (2009). The effective size of bryophyte populations. J Theor Biol 258: $121-126$.

Bernasconi G (2003). Seed paternity in flowering plants: an evolutionary perspective. Perspect Plant Ecol Evol Syst 6: 149-158.

Bisang I, Ehrlén J, Hedenäs L (2004). Mate limited reproductive success in two dioicous mosses. Oikos 104: 291-298.

Cornell SJ, Tregenza T (2007). A new theory for the evolution of polyandry as a means of inbreeding avoidance. Philos Trans R Soc Lond B Biol Sci 274: 2873-2879.

Cronberg N, Rydgren K, Økland RH (2006). Clonal structure and genet-level sex ratios suggest different roles of vegetative and sexual reproduction in the clonal moss Hylocomium splendens. Ecography 29: 95-103.

Ehrlén J, Bisang I, Hedenäs L (2000). Costs of sporophyte production in the moss, Dicranum polysetum. Plant Ecol 149: 207-217.

Ellstrand NC, Marshall DL (1986). Patterns of multiple paternity in populations of Raphanus sativus. Evolution 40: 837-842.

Eppley SM, Taylor PJ, Jesson LK (2007). Self-fertilization in mosses: a comparison of heterozygote deficiency between species with combined versus separate sexes. Heredity 98: 38-44.

Fan JB, Oliphant A, Shen R, Kermani BG, Garcia F, Gunderson KL et al. (2003). Highly parallel SNP genotyping. Cold Spring Harb Symp Quant Biol 68: 69-78.

Ghiselin MT (1974). The Economy of Nature and the Evolution of Sex. University of California Press: Berkeley.

Grimme A (1903). Über die Blütezeit deutscher Laubmoose und die Entwickelungsdauer ihrer Sporogone. Hedwigia 42: 1-75.

Hedenäs L, Bisang I (2011). The overlooked dwarf males in mosses - unique among green land plants. Perspect Plant Ecol Evol Syst 13: 121-135.

Hedenäs L, Bisang I (2012). Sex expression and sex ratios in dwarf male-producing pleurocarpous mosses - have we missed something? Plant Ecol Divers 5: 87-393.

Hughes JG (1979). The occurrence of polysety in relation to the number of archegonia in the female inflorescences of Phascum cuspidatum Hedw. J Bryol 10: 553-560

Jesson LK, Perley DS, Cavanagh AP, Cameron JA, Kubien DS (2012). Mating and fitness consequences of sexual system in the moss Atrichum undulatum sl (Polytrichaceae). Int J Plant Sci 173: 16-25.

Johnson MG, Shaw AJ (2015). Genetic diversity, sexual condition, and microhabitat preference determine mating patterns in Sphagnum (Sphagnaceae) peat-mosses. Biol J Linn Soc 115: 96-113.

Korbecka G, Klinkhamer PGL, Vrieling K (2002). Selective embryo abortion hypothesis revisited - a molecular approach. Plant Biol 4: 298-310.

Lieske K (2010). Vegetative reproduction and clonal diversity in pleurocarpous mosses (Bryopsida) of xeric habitats. Doctoral dissertation, Freie Universität Berlin.

Longton RE (1962). Polysety in the British bryophyta. T Brit Bryol Soc 4: 326-333.

Longton RE, Schuster RM (1983). Reproductive biologyln:Schuster RM(ed) New Manual of Bryology vol. 1, Hattori Botanical Laboratory: Nichinan. pp 386-462.

Longton RE (1994). Reproductive biology in bryophytes: the challenge and the opportunities. J Hattori Bot Lab 75: 1-13.

McDaniel SF, Perroud PF (2012). Invited perspective: bryophytes as models for understanding the evolution of sexual systems. Bryologist 115: 1-11.

Mishler BD, Newton AE (1988). Influences of mature plants and desiccation on germination of spores and gametophytic fragments of Tortula. J Bryol 15: 327-342.

Mogensen GS (1981). The biological significance of morphological characters in bryophytes: the spore. Bryologist 84: 187-207.

Pannell JR, Labouche AM (2013). The incidence and selection of multiple mating in plants. Philos Trans $R$ Soc Lond B Biol Sci 368: 20120051.

Perroud PF, Cove DJ, Quatrano RS, McDaniel SF (2011). An experimental method to facilitate the identification of hybrid sporophytes in the moss Physcomitrella patens using fluorescent tagged lines. New Phytol 191: 301-306.

Pichonet A, Gradstein SR (2012). Male dwarfism in the genus Dicranum (Dicranaceae)a review. Cryptogam Bryol 33: 299-311.

Price TAR, Hodgson DJ, Lewis Z, Hurst GDD, Wedell N (2008). Selfish genetic elements promote polyandry in a fly. Science 322: 1241-1243.

$\mathrm{R}$ Development Core Team (2005). R: A Language and Environment for Statistical Computing. R Foundation for Statistical Computing: Vienna, Austria. Avalilable from: http://www.R-project.org.

Ramsay HP (1985). Cytological and sexual characteristics of the moss Dicranoloma Ren. Monogr Syst Bot Mo Bot Gard 11: 93-110.

Rosengren F, Cronberg N (2014). The adaptive background of nannandry: dwarf male distribution and fertilization in the moss Homalothecium lutescens. Biol J Linn Soc 113: 74-84.

Rosengren F, Cronberg N (2015). Selective spore germination on shoots of Homalothecium lutescens, a moss with dwarf males. Biol Lett 11: pii: 20150427 
Rosengren F, Cronberg N, Reitalu T, Prentice HC (2014). Sexual reproduction in the phyllodioicous bryophyte Homalothecium lutescens (Hedw.) H. Rob. in relation to habitat age, growth conditions and genetic variation. J Bryol 36: 200-208.

Sagmo Solli IM, Söderström L, Bakken S, Flatberg KI, Pedersen B (1998). Reproductive phenology of Dicranum majus in central Norway. J Bryol 20: 311-321.

Stark LR, Stephenson AG (1983). Reproductive biology in Entodon cladorrhizans (Bryopsida, Entodontaceae). II. Resource-limited reproduction and sporophyte abortion. Syst Bot 8: 389-394.

Stark LR, Mishler BD, McLetchie DN (2000). The cost of realized sexual reproduction: assessing patterns of reproductive allocation and sporophyte abortion in a desert moss. Am J Bot 87: 1599-1608.

Sundberg S (2005). Sporophyte size positively influences short-range spore dispersal in Sphagnum, but what happens further away? Oikos 108: 115-124.
Szövényi P, Devos N, Weston DJ, Yang X, Hock Z, Shaw JA et al. (2014). Efficient purging of deleterious mutations in plants with haploid selfing. Genome Biol Evol 6: 1238-1252.

Szövényi P, Ricca M, Shaw AJ (2009). Multiple paternity and sporophytic inbreeding depression in a dioicous moss species. Heredity 103: 394-403.

Taylor PJ, Eppley SM, Jesson LK (2007). Sporophytic inbreeding depression in mosses occurs in a species with separate sexes but not in a species with combined sexes. Am J Bot 94: 1853-1859.

UniProt Consortium (2014). UniProt: a hub for protein information. Nucleic Acids Res; e-pub ahead of print 27 October 2014; doi:10.1093/nar/gku989.

Van der Velde M, During HJ, Van de Zande L, Bijlsma R (2001). The reproductive biology of Polytrichum formosum: clonal structure and paternity revealed by microsatellites. Mol Ecol 10: 2423-2434.

Vollrath F (1998). Dwarf males. Trends Ecol Evol 13: 159-163.

Supplementary Information accompanies this paper on Heredity website (http://www.nature.com/hdy) 